\title{
How Meningococcal disease affect a person? Serious life threatening complications
}

\author{
HMM Prasanthie ${ }^{1}$, KHPUD De Silva ${ }^{2}$ \\ ${ }^{1}$ Registrar in Medicine, ${ }^{2}$ Consultant Physician, Teaching Hospital, Karapitiya, Galle.
}

\section{Case report}

A 19 year-old navy soldier who had headache and backache for three days, fever for one day became unconscious following abnormal behaviour for about three hours. On examination he was febrile, unconscious and there was a bluish tinge over the tips of toes. Focal fits developed over the right side of the body. There was right sided hemiparesis. There was no neck stiffness. He was in impending respiratory failure with an oxygen saturation of $40 \%$. Examination of the cardiovacular system was normal except for a sinus tachycardia. Clinically he had acute respiratory distress syndrome and was transferred to the intensive care unit for ventilation.

On the second day he developed a necrotic purpuric rash over the upper limbs with dry gangrene of the toes, hypotension and gum bleeding.

\section{Investigations}

The total WBC was $20,000 / \mathrm{mm}^{3}$ with $98 \%$ neutrophils and the platelet count was 50,000 $/ \mathrm{mm}^{3}$. Blood picture showed severe neutrophilia, low platelets and fragmented red cells. Patient's prothrombin time was more than 180 seconds and the APPT was 76.5 seconds. D - dimers was $1.6 \mathrm{mg} / \mathrm{L}$ Renal function tests revealed blood urea of $75 \mathrm{mg} / \mathrm{dL}$, serum creatinine of 1.6 $\mathrm{mg} / \mathrm{dL}$, serum of $\mathrm{Na}^{+}-138 \mathrm{mmol} / \mathrm{L}$ and serum $\mathrm{K}^{+}$of $4.9 \mathrm{mmol} / \mathrm{L}$. Cerebrospinal fluid [CSF] analysis showed protein of $160 \mathrm{mg} / \mathrm{dL}$, polymorphs $-730 / \mathrm{mm}^{3}$, lymphocytes $-10 / \mathrm{mm}^{3}$, sugar of $2.2 \mathrm{mmol} / \mathrm{L}$ and the random blood sugar of $6.9 \mathrm{mmol} / \mathrm{L}$. Blood test for meningococcal antigen was positive. Chest X-ray showed diffuse alveolar shadows compatible with acute respiratory distress. Non contrast CT scan of the brain showed a venous infarction in the left parietal lobe. Audiometry indicated complete deafness of right ear and sensory neural deafness of left ear.

The above findings were compatible with meningococcal septicaemia complicated by acute respiratory distress, meningitis, disseminated intravascular coagulation, cerebral venous infarction, gangrene of toes and deafness.

The patient was treated with IV ceftriaxone, phenobarbitone, fresh frozen plasma, vitamin $\mathrm{K}$ and inotropes. The patient recovered but there was hearing loss. Left distal phalanges of second, third and fourth toes had to be amputated.

\section{Discussion}

Meningococcal disease is rare, but serious bacterial infections caused by Neisseria Meningitides. There are thirteen serogroups of which sero group ' $\mathrm{Y}$ ' is associated with outbreaks among military personnel ${ }^{1}$.

Meningococcemia is characterized by an abrupt onset of fever and petechial rash or necrotic purpuric rash which may progress to purpura fulminans, hypotension, acute adrenal haemorrhage and multiorgan failure due to septic emboli ${ }^{2}$.

Antigen test for blood and CSF, Gram stain of CSF and aspirate from skin lesions helps early diagnosis.

IV penicillin and ceftriaxone are effective antibacterial agents which should commence as early as possible ${ }^{3}$.

Poor prognostic features are coma on admission, rapidly coalescing purpuric rash and signs of shock. Nineteen percent survivors have sequelae like hearing loss, neurologic disability, amputation of limbs and renal failure ${ }^{2}$. 
The learning point from this case is that prompt clinical suspicion and early antibiotic therapy can save the patients lives of rare serious illnesses.

\section{References}

1. Smilack JD, Group - Y meningococcal disease; twelve cases at an Army Training Center. Ann Intern Med 1974; 81: 740-5.
2. Galaid EI, Cheru CE, Marr JS, Schae S, Barone J, Lec W. Meningococcal disease in New York City, 1973 to 1978; recognition of groups $\mathrm{Y}$ and $\mathrm{W}-135$ as frequent pathogens. JAMA 1980; 244: 2167-71.

3. Perkins BA, New opportunities for prevention of meningococcal disease. JAMA 2000; 283: 2842-3. 